\title{
Letter \\ Is fibromyalgia a cardiovascular disease? A comment on Martinez-Lavin's review 'Stress, the stress response system, and fibromyalgia'
}

\author{
Francisco Hélder C Félix ${ }^{1}$ and Juvenia Bezerra Fontenele ${ }^{2}$ \\ 1Department of Biophysiology and Pharmacology, Faculdade de Medicina de Juazeiro do Norte, Juazeiro do Norte, CE, Brazil \\ 2Faculdade Católica Rainha do Sertão, Quixadá, CE, Brazil
}

Corresponding author: Francisco Hélder C Félix, helderfelix@uol.com.br

Published: 31 October 2007

Arthritis Research \& Therapy 2007, 9:404 (doi:10.1186/ar2296)

This article is online at http://arthritis-research.com/content/9/5/404

c) 2007 BioMed Central Ltd

See related review article by Martinez-Lavin, http://arthritis-research.com/content/9/4/216

Fibromyalgia syndrome (FMS) is a mysterious condition with uncertain physiopathogenesis. Despite its hermeneutic problems, FMS and related afflictions are responsible for the majority of family medicine and rheumatological medical office appointments. In spite of the skepticism of some, it seems that the medical science community has accepted FMS as a valid, unique clinical diagnosis and the main theory explaining it (the central sensitization model (CSM)) may relate to many chronic pain states.

The CSM actually labels not a single unified hypothesis but, rather, a group of evidence-based central nervous system (CNS)-centered physiopathogenesis hypotheses for FMS. It constitutes the only model capable of explaining the majority of symptoms of FMS and predicts that CNS-acting agents are the most effective drugs in its treatment. Despite its success, many questions still need clarifying. What is the exact nature of the CNS alteration that is expressed as central sensitization? Why does it occur? What are its causes? And are there any genetic alterations that predispose to it?

Martinez-Lavin's review on FMS and dysautonomia [1] proposes a model that could explain FMS in terms of a sympathetically maintained neuropathic pain syndrome. It has the virtue of explaining the possible mechanisms behind CSM. Besides its conceptual and experimental gaps, we must not discard it without meticulous scrutiny through experimentation. The effort to get closer to a mechanistic, complete model of the CSM and FMS will certainly be rewarding since the need for a theoretical framework is critical in the study of FMS and other related chronic pain states.

We recently reported our own FMS causation model based on the experimental findings of Martinez-Lavin and others [2].
Briefly, we noted that there is probably a close relationship between FMS and related diseases and cardiovascular alterations, especially dysautonomia. The pattern, as noted also by Martinez-Lavin, involves not only sympathetic basal overactivity, but also sympathetic blunted responses to stimuli such as orthostatic challenge. Stewart and colleagues [3] have published many articles on orthostatic intolerance and its relationship to chronic fatigue syndrome, a disease closely related to FMS. His team and others think that dysautonomic alterations in orthostatic intolerance and chronic fatigue syndrome (described as similar to the findings associated with FMS) stem from microvascular reactivity alterations that lead to venous pooling in dependent extremities. Their main concept is of a 'relative thoracic hypovolemia' that determines secondary dysautonomia in orthostatic intolerance and probably chronic fatigue syndrome. Based on these and other findings, we proposed a cardiovascular FMS model, relating cardiovascular and nociception neural modulation as a possible cause of the CSM.

Do the experimental data as reviewed by Martinez-Lavin provide support for a cardiovascular model of FMS and related diseases? It may be so, but we need more experimentation to try these new ideas. Recent publications suggest that FMS patients more frequently have metabolic syndrome, and a hyperadrenergic state with blunted epinephrine secretion [4]. In addition, elevated body mass index correlated with secondary FMS [5]. Finally, neuroimaging techniques are disclosing a possible relationship between FMS and neurodegeneration [6]. Could it be that FMS patients have a neurovascular disease associated with CSM? Only time and more knowledge will tell. 


\section{Competing interests}

The authors cite their own work on the subject that is currently in press. There are no potential sources of conflicts of interest.

\section{References}

1. Martinez-Lavin M: Biology and therapy of fibromyalgia: Stress, the stress response system, and fibromyalgia. Arthritis Res Ther 2007, 9:216.

2. Fontenele JB, Félix FHC: Fibromyalgia and related medically unexplained symptoms: a lost link between cardiovascular and nociception modulation? J Musculoskeletal Pain, in press.

3. Stewart J, Taneja I, Medow MS: Reduced central blood volume and cardiac output, and increased vascular resistance during static handgrip exercise in postural tachycardia syndrome. Am J Physiol Heart Circ Physiol 2007, in press.

4. Loevinger BL, Muller D, Alonso C, Coe CL: Metabolic syndrome in women with chronic pain. Metabol Clin Exper 2007, 56:8793.

5. Chaiamnuay S, Bertoli AM, Fernández M, Apte M, Vilá LM, Reveille JD, Alarcón GS: The impact of increased body mass index on systemic lupus erythematosus. Data from LUMINA, a multiethnic cohort. J Clin Rheumatol 2007, 13:128-133.

6. Kuchinad A, Schweinhardt P, Seminowicz DA, Wood PB, Chizh $\mathrm{BA}$, Bushnell MC: Accelerated brain gray matter loss in fibromyalgia patients: premature aging of the brain? J $\mathrm{Neu}^{-}$ rosci 2007, 27:4004-4007. 